\title{
Understanding the Left Right Judgement Test: A Literature Review
}

\author{
Asall Kim ${ }^{1,2}, \mathrm{PT}, \mathrm{BPT}$, Chung-hwi $\mathrm{Yi}^{3}, \mathrm{PT}, \mathrm{PhD}$ \\ ${ }^{1}$ Department of Physical Therapy, The Graduate School, Yonsei University, Wonju, ${ }^{2}$ Department of Rehabilitation Medicine, Seoul National \\ University Bundang Hospital, Seongnam, ${ }^{3}$ Department of Physical Therapy, College of Software and Digital Healthcare Convergence, Yonsei \\ University, Wonju, Korea
}

\author{
Article Info \\ Received September 15, 2021 \\ Revised September 29, 2021 \\ Accepted October 1, 2021 \\ Corresponding Author \\ Chung-hwiYi \\ E-mail: pteagle@yonsei.ac.kr \\ https://orcid.org/0000-0003-2554-8083
}

\section{Key Words}

Body image

Functional laterality

Judgment

Rehabilitation
Background: The body schema, which is constantly updated using somatosensory information, enables accurate movement. Since pain is reported as a possible source to alter the body schema, the left right judgement test (LRJT) has been widely used in the pain rehabilitation. However, there was a lack of consistency in the effect of the pain on the LRJT results, and for the effect of the LRJT as a part of intervention programs for pain patients. The deeper understand of the LRJT is necessary for better reproducibility, and to expand the therapeutic applications of the LRJT in the pain and musculoskeletal rehabilitation.

Objects: This literature review aimed to understand the LRJT and to study the potential of the LRJT for therapeutic applications.

Methods: The PubMed database was searched for studies relevant to LRJT. To establish the query set, the term was regarded from various perspectives.

Results: The selected studies were classified into three categories: LRJT development, factors influencing LRJT, and therapeutic applications.

Conclusion: Left right judgement test is the evaluation tool for the integrity of body schema as well as a tool for implicit motor imagery. Pain, proprioception, and other factors influence the performance of the LRJT.

\section{INTRODUCTION}

The left right judgement test (LRJT) requires a mental rotation to determine whether the presented body part image is left or right side [1-3]. As this mental rotation activates similar area of motor cortex for actual limb movement, it seems to reflect the integrity of cortical representations. The cortical representation is also known as body schema which describes the specific frame of the body movement.

Since the concept of "postural schemata" has been introduced [4], the representations of the body have been studied in various research fields. Although there is an argument of the body schema definition [5], it has been largely agreed upon that the body schema is a knowledge of body size and position for action. The body schema is also constantly and unconsciously updated to allow proper postural control and perform accurate motor execution. While somatosensory stimuli such as tactile input, proprioception and vision is described as sources for updating the body schema, the critical source of the body schema is proprioception [5].

Since pain has also been reported as a source to manipulate the body schema [6,7], the LRJT has been used in pain science to test the body schema of the pain patients or to reduce pain as a part of intervention programs. However, the effect of pain on the body schema [8] and the effect of the pain intervention using the LRJT for chronic regional pain syndrome (CRPS) [9] was controversy. The ambiguous results were also observed in the rehabilitation study for the knee osteoarthritis (OA) [10]. Moreover, it seemed reasonable to expect the distorted body schema after the brain damage such as stroke because the body schema is stored in the brain; however, the relationship between the body schema and the motor function was also obscure [11]. This controversy might because of the complexity of the body schema. Based on the definition body schema, other somatosensory information influence on the LRJT results. Hence, the application of the LRJT will be consistent and will 
be extended with a comprehensive understanding of its nature.

Therefore, the study purpose was to understand the LRJT, to study factors related to the LRJT results, and to investigate the potential of its therapeutic applications.

\section{MATERIALS AND METHODS}

\section{Search Terms}

The LRJT has been variously named. Originally, it was introduced as a "laterality task;", subsequently, it was changed into the "left right judgement test", "left right recognition test" or "left right hand judgement". The usage of "judgement" or "recognition" depended on the country, hence, an operator, “*”, was used to cover the difference. We only searched published studies in English. Table 1 lists the established query set.

\section{Search Strategy and Study Selection}

Studies were identified using the PubMed database. As a result, 141 studies were identified. Among them, only English written studies that published since 2000 and included in the first and second quartiles of the Journal Citation Report were selected for present study. From the 98 studies, we excluded studies that did not have full text, those that contained left right visual or acoustic judgement test, and those that conducted a LRJT only with letters or object images which did not belong to any human body part. A total of 63 studies were included in the present study.

Table 1. Searching queries

\begin{tabular}{cl}
\hline Search number & \multicolumn{1}{c}{ Query } \\
\hline 1 & "left/right judg*" \\
2 & "left/right hand judg*" \\
3 & "left/right recog*" \\
4 & "laterality task" \\
5 & $\# 1$ or \#2 or \#3 or \#4 or \#5 \\
\hline
\end{tabular}

\section{RESULTS}

After selection procedure, studies were classified into three categories: (1) development of LRJT, (2) factors influencing LRJT, and (3) interventional application. The level of evidence was classified into the one of five levels (Table 2). We defined each level as follow; Level 1: randomized controlled trials or meta-analyses of randomized trials; Level 2: poorly designed randomized controlled trials or prospective cohort studies or meta-analyses of Level 2 studies; Level 3: case-control studies; Level 4: case-series; Level 5: case report or expert opinion. For convenience, both laterality and left right recognition tests were written as the LRJT in this study.

\section{Research for Development of the LRJT}

7 studies were included in this section. One study explained the background science of LRJT [12], while another study reported neurological evidence for the LRJT [13]. Two studies investigated reliability and validity of various versions of the LRJT [14,15]. Finally, two debating letters [16,17] and one research [18] were included in this section because they were concerned about developing the LRJT with other body parts.

\section{Research for Factors Influencing LRJT}

46 studies were classified into five categories: 1) demographic factors, 2) physical configurations, 3) visual information, 4) somatosensory information, and 5) neurologic impairment. Table 3 [6,7,19-62] shows each classification and factor. In addition, one meta-analysis [8] was also included in this section. Therefore, a total of 47 studies were categorized into this section.

\section{Research for Interventional Application}

Among the pooled studies, the LRJT was used in rehabilitation sessions for knee OA [10], stroke [11,63,64], and CRPS

Table 2. The number of articles included in this review

\begin{tabular}{|c|c|c|c|c|c|c|}
\hline \multirow{2}{*}{ Classification } & \multicolumn{5}{|c|}{ Level of evidence $^{a}$} & \multirow{2}{*}{ Total } \\
\hline & 1 & 2 & 3 & 4 & 5 & \\
\hline Development of LRJT & & & 1 & 4 & 2 & 7 \\
\hline Factors influencing LRJT & & 1 & 40 & 5 & 1 & 46 \\
\hline Intervention application & 2 & 4 & 1 & 1 & 1 & 9 \\
\hline
\end{tabular}

LRJT, left right judgement test. ${ }^{~}$ Level 1: randomized controlled trials or meta-analyses of randomized trials; Level 2: poorly designed randomized controlled trials or prospective cohort studies, or meta-analyses of Level 2 studies; Level 3: case-control studies; Level 4: case-series; Level 5: case report or expert opinion. 
Table 3. Influencing factors to left right judgement test

\begin{tabular}{ll}
\hline \multicolumn{1}{c}{ Classifications } & \multicolumn{1}{c}{ Factors } \\
\hline Demographic factors & Sex [19] \\
& Age [20-22] \\
& Handedness [23-25] \\
Physical configurations [26] & Amputation \\
& Prosthesis \\
& Congenital limb loss \\
Visual information & Perspective [27,28] \\
Somatosensory information & \\
Proprioception & Short-term immobilization [29-31] \\
& Brachial plexus anesthesia [32] \\
& Usual practice [33,34] \\
& Ligament deficit [35] \\
& Dizziness [36] \\
& Upper limb pain [6,37-44] \\
Pain & Lower limb pain [7,45-48] \\
& Fibromyalgia [49] \\
& Back and neck pain [50-53] \\
& Facial pain [54] \\
& Mild cognitive impairment [55] \\
& Eating disorder [56] \\
Neurologic impairment, & Asperger syndrome [57] \\
psychological and & Locked in syndrome [58,59] \\
behavior disorder & Developmental coordination disorder \\
& [60] \\
& Asomotognosia [61] \\
& Spinal cord injury [62] \\
\hline &
\end{tabular}

[65-67]. In addition, the short-term immobilized participants conducted the LRJT to investigate the effect of the motor imagery practice [68]. A meta-analysis [9] were also included in this section. Therefore, a total of 9 studies were included.

\section{DISCUSSION}

\section{Development of the LRJT}

Breckenridge et al. [12] developed an LRJT for shoulder based on neurological and behavioral science. The cortical body matrix describes the regulation and protection of the body at behavioral levels, in which disruption may induce pain and swelling, and alter perception of affected body size and delay sensory processing. The cortical body matrix is based on the concept of working body schema [4] which describes proprioceptive representations and the integration of the motor process. The disruption of the working body schema is associated with unresolved chronic pain. As Parsons [1-3] reported that using implicit motor imagery, which activated the primary motor cortex [13], was a common method to investigate the integrity of the working body schema. When performing an LRJT, one immediately judges whether the shown body images are on the left or the right side. Before drawing conclusions, confirmation must be obtained by mentally rotating the presented images. The time taken for the final selection and proportion of correct judgments were recorded. A slow response time or increased failure rate indicated delayed processing stimuli and impaired cortical proprioceptive representations, respectively.

Since the test requires presenting stimuli and recording response, desktop programs such as e-prime 2.0 (Psychology Software Tools, Pittsburgh, PA, USA), MATLAB (The MathWorks, Inc., Natick, MA, USA) and desktop version LRJT (Neuro-Orthopedic Institute, Adelaide, Australia) are available. The Neuro-Orthopedic Institute group provides a card-based LRJT and tablet-based LRJT [14] for hand, foot, neck, shoulder, back and knee. Tablet version LRJT displays one decimal place mean response time in seconds and the mean accuracy in percentage, while the desktop version displays the mean response time in milliseconds and every response time and accuracy for each stimulus. Although the desktop version LRJT is not available [44], the tablet version LRJT can be used with poor to good reliability $[14,15]$. Table 4 shows the intraclass coefficient, the standard error of measurement, and the minimal detectable differences for various LRJT version.

While the mental transformation of hand or foot images is believed to involve body schema [2,3], the mental rotation of other body parts, such as the neck, shoulder and back not only requires the body schema, but also the body structural description which reflects the ability to visually match body parts spatially $[16,17]$. Therefore, it is argued whether the LRJT for the shoulder and back, which contains multiple body parts, elicits motor imagery or not [17]. Alazmi et al. [18] also argued that the LRJT for the back did not elicit motor imagery because the biomechanical effect was not observed. In other words, reported response time and accuracy were faster and higher when it should be slower and lower as the larger trunk movement of the image. Although the evidence of the distorted body schema for the affected body part in pain patients was accumulated, the possibility of not using motor imagery still exists [16]. Therefore, the LRJT for the hand and the foot can be implemented to evaluate the body schema because it uses an implicit motor imagery, whereas the LRJT which contains multiple body parts should be implemented with caution. 
Table 4. Reliability and validity of left right judgement test

\begin{tabular}{|c|c|c|c|c|c|}
\hline & \multirow{2}{*}{ Category } & \multicolumn{4}{|c|}{ Intraclass coefficient (standard error of measurement) } \\
\hline & & Accuracy, \% & MDD & Response time, $\mathrm{s}$ & MDD \\
\hline \multirow[t]{3}{*}{ Reliability $[14,15]$} & Card-based (hand) & $0.774(1.85)$ & 5.14 & $0.843(0.16)$ & 0.44 \\
\hline & Tablet-based (hand) & $0.551(4.94)$ & 13.70 & $0.897(0.13)$ & 0.37 \\
\hline & Tablet-based (back, neck, foot) & $0.824(0.846)$ & 2.345 & $0.903(0.017)$ & 0.047 \\
\hline \multirow[t]{2}{*}{ Validity [15] } & Tablet-based (back, neck, foot) & $0.781(1.006)$ & 2.789 & $0.880(0.027)$ & 0.074 \\
\hline & Tablet-based (hand) & $0.909(0.604)$ & 1.841 & $0.836(0.147)$ & 0.409 \\
\hline
\end{tabular}

MDD, minimal detectable difference.

\section{Factors Influencing the LRJT}

\section{1) Demographic factors}

There were differences observed between males and females during the LRJT [19]. While males were fast in distinguishing the palm side, females were fast in determining the back side. Males and females were equally fast in judging the medial side of the palm. Nevertheless, the effect was large in males. These two findings suggested that males were familiar with the palm side of the hand, whereas females were familiar with the back side. Moreover, both sexes were influenced by biomechanical constraints; however, differences existed between them. Furthermore, they utilized motor simulation processes differently during visual motor imagery.

The LRJT results are also influenced by age. Raimo et al. [20] investigated body schema with the LRJT in various age groups. They found that adults over 60 years of age showed a lower accuracy of the LRJT compared with that of younger adults, and the accuracy of LRJT shown by those under 10 years of age and over 60 years of age was lower than that shown by young and middle adult groups [21]. This age-dependent change was also observed in the test development study [12]. Zapparoli et al. [22] designed a functional magnetic resonance imaging (fMRI) study to compare young and older adults during the LRJT. They found no group differences, whereas occipito-temporal regions were additionally activated in the older adults. The authors described this as a compensatory process for aging.

Handedness is also a possible reason for this difference. Takeda et al. [23], however, reported that both right- and lefthanded participants showed similar response times for each image rotation angle, which indicated that both were able to mentally rotate images. The only difference was that the righthanded participants identified left-hand images slower than left-handed ones did because the hand motor skills of the right-handed participants were more lateralized than those of the left-handed ones. Similar response times may also be explained using the results of the fMRI study. Mellet et al. [24] confirmed that a shift away was exhibited during the LRJT in the sensorimotor cortex, including the motor cortex. This shift was affected by the presented hand images, but not by handedness. Similarly, skin color did not affect the motor imagery ability [25]. Based on these studies, it was suggested that sex and age should be considered for interpreting LRJT results.

\section{2) Physical configurations}

Nico et al. [26] investigated the ability of motor imagery in population with limb loss. Compared with controls, participants with dominant limb loss made more error and took more time to respond. If participants with dominant limb loss wore prostheses, their response correctness and time were decreased and delayed, respectively. However, there was no effect when participants with non-dominant limb loss wore prostheses. Furthermore, it was interesting that the LRJT results of participants with congenital limb loss did not statistically differ from controls. These findings suggest that the ability of motor imagery is developed by the growth, once the ability is matured, the loss of dominant limb significantly affected the ability of motor imagery.

\section{3) Visual information}

The term biomechanical effect or constraints describes the delayed response time required to take inverted images. This effect is an evidence for mental rotation during the LRJT [2]. Brady et al. [27] investigated the effect of perspective during the LRJT. Usually, the LRJT contains body parts image with $0^{\circ}$, clockwise, counterclockwise, and $180^{\circ}$ rotation. They classified various rotation angles into first-person view $\left(0^{\circ}, 45^{\circ}, 90^{\circ}\right.$, $\left.270^{\circ}, 315^{\circ}\right)$ and the third-person view $\left(135^{\circ}, 180^{\circ}, 225^{\circ}\right)$. The first-person view reflects one's own hands; thus, it looks familiar. Contrastingly, the third-person view reflects the third per- 
son's perspective; thus, it looks awkward. They concluded that motor imagery was commonly used in the first-person view, whereas a shift away occurred in the third-person view.

This perspective difference was also reported in repetitive transcranial magnetic stimulation (rTMS) study. De Bellis et al. [28] applied rTMS to specific brain regions. They stimulated both side of the extrastriate body area (EBA), left ventral premotor cortex (vPM). The participant's LRJT performance improved after the stimulation of the left or right EBA, whereas no effect was found after vPM stimulation. It was also reported that right EBA and left EBA has a role in recognizing other hands and their own hands, respectively. Based on these studies, it was suggested that the perspective must be considered during the LRJT.

\section{4) Somatosensory information}

\section{(1) Proprioceptive information}

It is well documented that the non-usage of a limb influences motor imagery processes. Usually, performance improves by repetition, whereas short-term immobilization prevents improvement. Based on this evidence, the effect of the dominant hand immobilization was compared to that of non-dominant hand immobilization [29]. It was reported that both the dominant hand immobilized group and the non-dominant hand immobilized group were slower than controls in the post-test, while the dominant hand immobilized group was significantly slower than the non-dominant hand immobilized group. An inter-limb transfer phenomenon was also reported because both immobilized groups showed little improvement in distinguishing contralateral hand, which disappeared after short-term immobilization. This finding was also supported by another study [30]. This inter-limb transfer phenomenon was observed in the hand LRJT, but not in the foot LRJT. A large effect of an immobilizing dominant hand was also confirmed recently. Toussaint et al. [31] observed the grip-precision effect in dominant hand, which disappeared after short-term immobilization. In addition to immobilization, Silva et al. [32] conducted an experiment on inducing proprioceptive deficits using anesthesia. Twenty participants received regional anesthesia on their dominant side brachial plexus or non-dominant side brachial plexus. Anesthetized participants reported perceptual illusions, delay in the response time, and the inaccuracy of response compared to healthy ones. In addition, the effect of anesthesia was larger in the participants with anesthetized dominant side.
Although the effect of a usual practice of musical instruments, sport [33] or yoga [34] or a ligament deficit [35] on LRJT were investigated, no effect was found. Likewise, the effect of dizziness [36] was also investigated and no effect was found. Based on these studies, it can be concluded that a proprioceptive deficit induced by immobilization or anesthesia slows down the sensorimotor process and alters the body representations.

\section{(2) Pain}

Since Coslett et al. [6,7] established the evidence of the effect of pain on motor imagery, the LRJT has been widely used for research in cohorts with pain. Most studies were conducted in patients with upper limb pain [37-44], including frozen shoulder, hand OA, carpal tunnel syndrome, wrist pain and lateral epicondylitis. The performance of the LRJT in patients with low limb pain [45-48], fibromyalgia [49] back and neck pain [50-53], and facial pain [54] was also investigated. Except for two populations with tendinopathies [44,46], the integrity of body schema was distorted in populations with limb and facial pain. The effect of back and neck pain on the LRJT performance was controversial, which was consistent with the findings of a previously published meta-analysis study [8]. Although two-point discrimination test (TPDT) was usually conducted to investigate an alterations of primary somatosensory cortex (S1) representation $[37,38,40,41,45-47,49,51,53]$ and the results of TPDT was significantly difference from the healthy participants, the relationship between the LRJT and the TPDT was not statistically significant. Therefore, it can be suggested that peripheral pain may alter both motor and sensory cortical representations, but the interaction between two representations requires a further study.

\section{5) Neurologic impairment, psychological and behavior disorder}

We found that the LRJT was conducted to determine whether motor imagery was impaired in individuals with mild cognitive impairment [55], eating disorder [56], Asperger syndrome [57], locked in syndrome [58,59], developmental coordination disorder [60], asomatognosia [61], and spinal cord injury [62]. We confirmed impaired motor imagery in these cohorts, however, there were differences in severity.

Biomechanical effects are the key to understanding the impairment of motor imagery [2,3]. As stated, response time and response accuracy increase and decrease, respectively, at the 
awkward image presented. Awkward images correspond to totally inverted images or images presenting lateral side. In other words, the more the image seems to belong to others, the more response time it takes and the more mistakes are made. In accordance with the statement, biomechanical effects were not observed in population with Asperger syndrome [57], developmental coordination disorder [60], and spinal cord injury [62]. In contrast, a population with mild cognitive impairment [55] and eating disorder [56] demonstrated similar patterns as those in healthy participants. However, selective impairment was still observed in these cohorts. While mild cognitive impairment subjects showed delayed response for all image presented, a self-advantage effect disappeared in those with eating disorder. Healthy participants took a short time to distinguish images that looked like own hand than images that look like those of others. Likewise, patients with asomatognosia showed a significant difference in judging inverted dorsal side foot images [61]. In summary, motor imagery can be impaired by deficits of neurologic regions that govern motor processes and behavioral, cognitive, and psychological processes.

\section{Interventional Application}

Most studies investigated the effect of the specific program for CRPS. Two mirror therapy studies included because they conducted LRJT for outcome values. A recent study used the LRJT for an evaluation tool and a part of treatment regimen. Table 5 [10,11,63-67] shows the use of LRJT as an evaluation tool or a part of the intervention programs within pooled studies.

\section{1) Knee $O A$}

Based on LRJT science, Harms et al. [10] hypothesized that

Table 5. Application of left right judgement test

\begin{tabular}{lllc}
\hline \multicolumn{1}{c}{ Study } & Subject & Evaluation & $\begin{array}{c}\text { Part of } \\
\text { intervention }\end{array}$ \\
\hline Harms et al. [10] & Knee OA & Yes & Yes (BT) \\
Lundquist and Nielsen [11] & Stroke & Yes & No (MT) \\
Ding et al. [63,64] & Stroke & Yes & No (MVF) \\
Strauss et al. [65] & CRPS & Yes & Yes (GMI) \\
Johnson et al. [66] & CRPS & Yes & Yes (GMI) \\
Bean et al. [67] & CRPS & Yes & Yes (GMI) \\
Meugnot et al. [68] & Healthy & Yes & No (MIP) \\
\hline
\end{tabular}

OA, osteoarthritis; BT, brain-targeted treatment; MT, mirror therapy; GMI, graded motor imagery; MVF; mirror visual feedback; CRPS, chronic regional pain syndrome; MIP, motor imagery practice. brain-targeted intervention (BT) might be effective in population cohorts with OA. BT consisted of implicit motor imagery training and a two-point discrimination task. The control group received usual care which included (1) quadriceps activation and strengthening, (2) hip abduction exercise, (3) knee mobilization exercise, and (4) rectus femoris and gastrocnemius muscle stretching. After 2 weeks training, no significant improvements were detected for pain intensity or joint function. Only fear avoidance beliefs were significantly decreased in both the groups. Interestingly, the accuracy of the LRJT in the usual care group was significantly improved. The authors inferred that the participants should focus on the affected knee during exercise, and exercise might improve joint proprioception, then it might alter cortical representation of the knee.

\section{2) Stroke}

Mirror therapy [11] and mirror visual feedback (MVF) [63] are possible interventions for neurorehabilitation. When the movement of an unaffected arm is reflected by a mirror, cortices governing the affected arm seem to be activated. Many variables have been studied to improve its effectiveness. Lundquist and Nielsen [11] focused on the impact of LRJT performance on the mirror therapy effect. The participants were trained for 10 days, and their motor assessment scale and two-point discrimination were assessed. The participants' outcomes improved, whereas the result of Spearman's rank correlation between LRJT performance and physical function were not significant. Ding et al. [63] investigated whether the camera technique could be applied to MVF. Compared with patients who received the conventional intervention, patients who received a camera-based MVF intervention significantly improved motor impairment. In the MVF group, patients with right-hemisphere damage showed greater restoration compared with patients with left-hemisphere damage. The response time was significantly decreased after the intervention only in the MVF group, authors explained that this was because motor imagery might have activated the prefrontal and premotor cortices. Based on this study, Ding et al. [64] announced protocol papers. They recorded the electroencephalogram signals during motor imagery tasks. But the study result has not been published, yet. Based on these studies, it can be concluded that mirror therapy shares similar principles with the LRJT, but the LRJT does not enhance the effect of mirror therapy. 


\section{3) CRPS}

The graded motor imagery (GMI) is a novel intervention based on neurologic and behavioral science that is designed for patients with CRPS. In fMRI study [65], CRPS patients showed reduced activities in the middle temporal area, primary sensorimotor area, and right putamen compared with those of healthy participants. After 6 weeks of GMI training, there was a decrease in the contralateral side $\mathrm{S} 1$ activity and an increase in the left ventral putamen activity. CRPS patients also showed an improvement in the performance measured by LRJT, which was positively associated with right parietal activity. However, this performance improvement was not consistent with the results of other studies. In a study, which revealed the effect of GMI program, both response time and accuracy were improved, while pain intensity did not [66]. In contrast, Bean et al. [67] conducted a multimodal pain program, including GMI, and they reported that CRPS severity, McGill pain questionnaire 2 score, the pain disability index score, all psychological measurement scores, body perception and limb ownership improved, while the LRJT performance did not. This inconsistency has also been reported in a meta-analysis study. Bowering et al. [9] synthesized previous articles and concluded that (1) the LRJT had never been used for an independent treatment, (2) GMI program appeared to be conducted in order, and (3) there was no evidence that the LRJT conducted in treatment for other chronic pain. Therefore, it can be suggested that the GMI program is effective when the therapist deeply understands the background science.

\section{4) Motor imagery practice (MIP)}

It has been repeatedly reported that short-term immobilization induces a delay in the motor imagery process [29-31]. With this line of evidence, sensorimotor representations of immobilized patients after surgery are disturbed. Therefore, it was suggested that patients should practice motor imagery during immobilization to maintain the integrity of sensorimotor representations. However, no study revealed the effects of there was no study to reveal the effect of MIP during immobilization. Meugnot et al. [68] conducted experiments to determine the type of MIP that would be effective during short-term immobilization. The participants' left hand was immobilized for 24 hours, before removal, they practiced different MIPs for 20 minutes. The first group did not practice, while other two groups practiced visual motor imagery or kinesthetic mo- tor imagery. It was confirmed that 24 hour-immobilization induced a delayed response time. It was found that response time of the kinesthetic motor imagery group was significantly faster than that of the group who did not practice. Therefore, kinesthetic MIP is recommended when movement is not possible for a short period time.

\section{CONCLUSIONS}

The LRJT for the hand and foot is a tool used to evaluate the body schema integrity and implicit motor imagery that activates similar cortex governing actual limb movement. It has been confirmed that the faulty proprioception and the pain of a limb disrupt the limb body schema. Although the effect of the LRJT as a part of pain intervention remains unclear, the exercise intervention may improve LRJT results. Therefore, the science of motor imagery and the LRJT may bridge the musculoskeletal symptoms and the neurologic feature. For example, it will be worth of studying the relationship between the LRJT results and the movement quality such as a movement accuracy and a movement trajectory. We hope that this study may help to move forward in the rehabilitation practice.

\section{ACKNOWLEDGEMENTS}

This study was supported by the "Brain Korea 21 FOUR Project", the Korean Research Foundation for Department of Physical Therapy in the Graduate School of Yonsei University.

\section{CONFLICTS OF INTEREST}

No potential conflict of interest relevant to this article was reported.

\section{AUTHOR CONTRIBUTIONS}

Conceptualization: AK, CY. Data curation: AK. Formal analysis: AK, CY. Visualization: AK, CY. Writing - original draft: AK. Writing - review \& editing: AK, CY.

\section{ORCID}

Asall Kim, https://orcid.org/0000-0002-1160-8252 


\section{REFERENCES}

1. Parsons LM. Imagined spatial transformation of one's body. J Exp Psychol Gen 1987;116(2):172-91.

2. Parsons LM. Imagined spatial transformations of one's hands and feet. Cogn Psychol 1987;19(2):178-241.

3. Parsons LM. Integrating cognitive psychology, neurology and neuroimaging. Acta Psychol (Amst) 2001;107(1-3):155-81.

4. Head H, Holmes G. Sensory disturbances from cerebral lesions. Brain 1911;34(2-3):102-254.

5. Cardinali L. Body Schema plasticity after tool-use. Villeurbanne, Université Claude Bernard Lyon I, Doctoral Dissertation. 2011.

6. Coslett HB, Medina J, Kliot D, Burkey AR. Mental motor imagery indexes pain: the hand laterality task. Eur J Pain 2010;14(10):1007-13.

7. Coslett HB, Medina J, Kliot D, Burkey A. Mental motor imagery and chronic pain: the foot laterality task. J Int Neuropsychol Soc 2010;16(4):603-12.

8. Breckenridge JD, Ginn KA, Wallwork SB, McAuley JH. Do people with chronic musculoskeletal pain have impaired motor imagery? A meta-analytical systematic review of the left/right judgment task. J Pain 2019;20(2):119-32.

9. Bowering KJ, O'Connell NE, Tabor A, Catley MJ, Leake HB, Moseley GL, et al. The effects of graded motor imagery and its components on chronic pain: a systematic review and metaanalysis. J Pain 2013;14(1):3-13.

10. Harms A, Heredia-Rizo AM, Moseley GL, Hau R, Stanton TR. A feasibility study of brain-targeted treatment for people with painful knee osteoarthritis in tertiary care. Physiother Theory Pract 2020;36(1):142-56.

11. Lundquist CB, Nielsen JF. Left/right judgement does not influence the effect of mirror therapy after stroke. Disabil Rehabil 2014;36(17):1452-6.

12. Breckenridge JD, McAuley JH, Butler DS, Stewart H, Moseley GL, Ginn KA. The development of a shoulder specific left/right judgement task: validity \& reliability. Musculoskelet Sci Pract 2017;28:39-45

13. Hyde C, Fuelscher I, Lum JA, Williams J, He J, Enticott PG. Primary motor cortex excitability is modulated during the mental simulation of hand movement. J Int Neuropsychol Soc 2017;23(2):185-93

14. Zimney KJ, Wassinger CA, Goranson J, Kingsbury T, Kuhn T, Morgan S. The reliability of card-based and tablet-based left/right judgment measurements. Musculoskelet Sci Pract 2018;33:105-9.

15. Williams LJ, Braithwaite FA, Leake HB, McDonnell MN, Peto DK, Lorimer Moseley G, et al. Reliability and validity of a mobile tablet for assessing left/right judgements. Musculoskelet Sci Pract 2019;40:45-52.

16. Breckenridge JD, McAuley JH, Butler DS, Stewart H, Moseley GL, Ginn KA. Reply to the letter to the editor 're: the development of a shoulder specific left/right judgement task: validity \& reliability'. Musculoskelet Sci Pract 2017;30:e88-9.

17. Punt TD. Re: the development of a shoulder specific left/right judgement task: validity \& reliability. Musculoskelet Sci Pract 2017;30:e87.

18. Alazmi L, Gadsby GE, Heneghan NR, Punt TD. Do trunk-based left/right judgment tasks elicit motor imagery? Musculoskelet Sci Pract 2018;35:55-60.

19. Conson M, De Bellis F, Baiano C, Zappullo I, Raimo G, Finelli C, et al. Sex differences in implicit motor imagery: evidence from the hand laterality task. Acta Psychol (Amst) 2020;203:103010.

20. Raimo S, Boccia M, Di Vita A, Cropano M, Guariglia C, Grossi D, et al. The body across adulthood: on the relation between interoception and body representations. Front Neurosci 2021;15:586684.

21. Raimo S, Di Vita A, Boccia M, Iona T, Cropano M, Gaita M, et al. The body across the lifespan: on the relation between interoceptive sensibility and high-order body representations. Brain Sci 2021;11(4):493.

22. Zapparoli L, Saetta G, De Santis C, Gandola M, Zerbi A, Banfi G, et al. When I am (almost) 64: the effect of normal ageing on implicit motor imagery in young elderlies. Behav Brain Res 2016;303:137-51.

23. Takeda K, Shimoda N, Sato Y, Ogano M, Kato H. Reaction time differences between left- and right-handers during mental rotation of hand pictures. Laterality 2010;15(4):415-25.

24. Mellet E, Mazoyer B, Leroux G, Joliot M, Tzourio-Mazoyer N. Cortical asymmetries during hand laterality task vary with hand laterality: a fMRI study in 295 participants. Front Hum Neurosci 2016;10:628.

25. Saetta G, Brugger P, Schrohe H, Lenggenhager B. Putting yourself in the skin of in- or out-group members: no effect of implicit biases on egocentric mental transformation. Front Psychol 2019;10:1338.

26. Nico D, Daprati E, Rigal F, Parsons L, Sirigu A. Left and right 
hand recognition in upper limb amputees. Brain 2004;127(Pt 1):120-32

27. Brady N, Maguinness C, Ní Choisdealbha A. My hand or yours? Markedly different sensitivity to egocentric and allocentric views in the hand laterality task. PLoS One 2011;6(8):e23316

28. De Bellis F, Trojano L, Errico D, Grossi D, Conson M. Whose hand is this? Differential responses of right and left extrastriate body areas to visual images of self and others' hands. Cogn Affect Behav Neurosci 2017;17(4):826-37.

29. Meugnot A, Toussaint L. Functional plasticity of sensorimotor representations following short-term immobilization of the dominant versus non-dominant hands. Acta Psychol (Amst) 2015;155:51-6.

30. Meugnot A, Agbangla NF, Toussaint L. Selective impairment of sensorimotor representations following shortterm upper-limb immobilization. Q J Exp Psychol (Hove) 2016;69(9):1842-50.

31. Toussaint L, Meugnot A, Bidet-Ildei C. Short-term upper limb immobilisation impairs grasp representation. Q J Exp Psychol (Hove) 2021;74(6):1096-102.

32. Silva S, Loubinoux I, Olivier M, Bataille B, Fourcade O, Samii $\mathrm{K}$, et al. Impaired visual hand recognition in preoperative patients during brachial plexus anesthesia: importance of peripheral neural input for mental representation of the hand. Anesthesiology 2011;114(1):126-34.

33. Dey A, Barnsley N, Mohan R, McCormick M, McAuley JH, Moseley GL. Are children who play a sport or a musical instrument better at motor imagery than children who do not? Br J Sports Med 2012;46(13):923-6.

34. Wallwork SB, Butler DS, Wilson DJ, Moseley GL. Are people who do yoga any better at a motor imagery task than those who do not? Br J Sports Med 2015;49(2):123-7.

35. Ismail SA, Simic M, Stanton TR, Pappas E. Motor imagery in high-functioning individuals with chronic anterior cruciate ligament deficiency: a cross-sectional study. Knee 2019;26(3):545-54

36. Wallwork SB, Butler DS, Moseley GL. Dizzy people perform no worse at a motor imagery task requiring whole body mental rotation; a case-control comparison. Front Hum Neurosci 2013;7:258.

37. Barbosa AM, José-Jandre Dos Reis F, Caseiro M, Barbero M, Falla D, Siriani de Oliveira A. Clinical evaluation of somatosensory integrity in people with chronic shoulder pain. Musculo- skelet Sci Pract 2021;53:102364.

38. Breckenridge JD, McAuley JH, Ginn KA. Motor imagery performance and tactile spatial acuity: are they altered in people with frozen shoulder? Int J Environ Res Public Health 2020;17(20):7464.

39. Breckenridge JD, McAuley JH, Moseley GL, Ginn KA. Is implicit motor imagery altered in people with shoulder pain? The shoulder left/right judgement task. Musculoskelet Sci Pract 2020;48:102159

40. Magni NE, McNair PJ, Rice DA. Sensorimotor performance and function in people with osteoarthritis of the hand: a casecontrol comparison. Semin Arthritis Rheum 2018;47(5):67682.

41. Mena-Del Horno S, Balasch-Bernat M, Dueñas L, Reis F, Louw A, Lluch E. Laterality judgement and tactile acuity in patients with frozen shoulder: a cross-sectional study. Musculoskelet Sci Pract 2020;47:102136.

42. Pelletier R, Higgins J, Bourbonnais D. Laterality recognition of images, motor performance, and aspects related to pain in participants with and without wrist/hand disorders: an observational cross-sectional study. Musculoskelet Sci Pract 2018;35:18-24.

43. Schmid AB, Coppieters MW. Left/right judgment of body parts is selectively impaired in patients with unilateral carpal tunnel syndrome. Clin J Pain 2012;28(7):615-22.

44. Wiebusch M, Coombes BK, Silva MF. Joint position sense, motor imagery and tactile acuity in lateral elbow tendinopathy: a cross-sectional study. Musculoskelet Sci Pract 2021;55:102422.

45. Summers SJ, Chalmers KJ, Wallwork SB, Leake HB, Moseley GL. Interrogating cortical representations in elite athletes with persistent posterior thigh pain - new targets for intervention? J Sci Med Sport 2021;24(2):135-40.

46. Tompra N, van Dieën JH, Plinsinga ML, Coppieters MW. Left/ right discrimination is not impaired in people with unilateral chronic Achilles tendinopathy. Musculoskelet Sci Pract 2021;54:102388.

47. Stanton TR, Lin CW, Bray H, Smeets RJ, Taylor D, Law RY, et al. Tactile acuity is disrupted in osteoarthritis but is unrelated to disruptions in motor imagery performance. Rheumatology (Oxford) 2013;52(8):1509-19.

48. Stanton TR, Lin CW, Smeets RJ, Taylor D, Law R, Lorimer Moseley G. Spatially defined disruption of motor imagery performance in people with osteoarthritis. Rheumatology 
(Oxford) 2012;51(8):1455-64.

49. Martínez E, Guillen V, Buesa I, Azkue JJ. A distorted body schema and susceptibility to experiencing anomalous somatosensory sensations in fibromyalgia syndrome. Clin J Pain 2019;35(11):887-93.

50. Wallwork SB, Leake HB, Peek AL, Moseley GL, Stanton TR. Implicit motor imagery performance is impaired in people with chronic, but not acute, neck pain. PeerJ 2020;8:e8553.

51. Meier R, Iten P, Luomajoki H. Clinical assessments can discriminate altered body perception in patients with unilateral chronic low back pain, but not differences between affected and unaffected side. Musculoskelet Sci Pract 2019;39:13643.

52. Bray H, Moseley GL. Disrupted working body schema of the trunk in people with back pain. Br J Sports Med $2011 ; 45(3): 168-73$

53. Heerkens RJ, Köke AJ, Lötters FJ, Smeets RJ. Motor imagery performance and tactile acuity in patients with complaints of arms, neck and shoulder. Pain Manag 2018;8(4):277-86.

54. von Piekartz H, Wallwork SB, Mohr G, Butler DS, Moseley GL. People with chronic facial pain perform worse than controls at a facial emotion recognition task, but it is not all about the emotion. J Oral Rehabil 2015;42(4):243-50.

55. Bourrelier J, Kubicki A, Rouaud O, Crognier L, Mourey F. Mental rotation as an indicator of motor representation in patients with mild cognitive impairment. Front Aging Neurosci 2015;7:238

56. Campione GC, Mansi G, Fumagalli A, Fumagalli B, Sottocornola S, Molteni M, et al. Motor-based bodily self is selectively impaired in eating disorders. PLoS One 2017;12(11):e0187342.

57. Conson M, Mazzarella E, Frolli A, Esposito D, Marino N, Trojano L, et al. Motor imagery in Asperger syndrome: testing action simulation by the hand laterality task. PLoS One 2013;8(7):e70734

58. Conson M, Pistoia F, Sarà M, Grossi D, Trojano L. Recognition and mental manipulation of body parts dissociate in locked-in syndrome. Brain Cogn 2010;73(3):189-93.

59. Conson M, Sacco S, Sarà M, Pistoia F, Grossi D, Trojano L. Se- lective motor imagery defect in patients with locked-in syndrome. Neuropsychologia 2008;46(11):2622-8.

60. Hyde C, Fuelscher I, Williams J, Lum JAG, He J, Barhoun P, et al. Corticospinal excitability during motor imagery is reduced in young adults with developmental coordination disorder. Res Dev Disabil 2018;72:214-24.

61. Saetta G, Zindel-Geisseler O, Stauffacher F, Serra C, Vannuscorps G, Brugger P. Asomatognosia: structured interview and assessment of visuomotor imagery. Front Psychol 2021;11:544544.

62. Fiori F, Sedda A, Ferrè ER, Toraldo A, Querzola M, Pasotti F, et al. Motor imagery in spinal cord injury patients: moving makes the difference. J Neuropsychol 2014;8(2):199-215.

63. Ding L, Wang X, Guo X, Chen S, Wang H, Jiang N, et al. Camera-based mirror visual feedback: potential to improve motor preparation in stroke patients. IEEE Trans Neural Syst Rehabil Eng 2018;26(9):1897-905.

64. Ding L, Wang X, Guo X, Chen S, Wang H, Cui X, et al. Effects of camera-based mirror visual feedback therapy for patients who had a stroke and the neural mechanisms involved: protocol of a multicentre randomised control study. BMJ Open 2019;9(3):e022828.

65. Strauss S, Barby S, Härtner J, Neumann N, Moseley GL, Lotze M. Modifications in fMRI representation of mental rotation following a 6 week graded motor imagery training in chronic CRPS patients. J Pain 2021;22(6):680-91.

66. Johnson S, Hall J, Barnett S, Draper M, Derbyshire G, Haynes L, et al. Using graded motor imagery for complex regional pain syndrome in clinical practice: failure to improve pain. Eur J Pain 2012;16(4):550-61.

67. Bean DJ, Johnson MH, Heiss-Dunlop W, Lee AC, Kydd RR. Do psychological factors influence recovery from complex regional pain syndrome type 1 ? A prospective study. Pain 2015;156(11):2310-8.

68. Meugnot A, Agbangla NF, Almecija Y, Toussaint L. Motor imagery practice may compensate for the slowdown of sensorimotor processes induced by short-term upper-limb immobilization. Psychol Res 2015;79(3):489-99. 